\title{
Potenciar a utilização de recursos no ensino e aprendizagem da matemática a partir da reflexão sobre a acção
}

\author{
Celina Tenreiro Vieira \\ Universidade de Aveiro, CIDTFF \\ cvieira@ua.pt
}

Resumo: Assumindo que na formação de professores de matemática, os recursos em contexto das práticas, devem ser um foco de atenção, no presente artigo foca-se o trabalho desenvolvido com professores envolvidos no Programa de Formação Contínua em Matemática para Professores do $1^{\circ}$ Ciclo do Ensino Básico Português. Neste contexto, a ênfase na dimensão dos recursos orientou-se, sobretudo, para a problematização e reflexão sobre recursos usados pelos professores na aula de matemática. Decorrente desse processo de reflexão partilhada, perspectivaram-se outros modos de exploração de tais recursos, no contexto do ensino e aprendizagem da matemática, para promover a sua eficácia didáctica.

Palavras-chave: Formação de professores; Recursos no ensino e aprendizagem da matemática; Ensino Básico.

\begin{abstract}
Assuming that in mathematics teacher education the resources in the classroom learning and teaching context must be a focus of attention, the present article describes the work developed with primary teachers involved in one Mathematics Inservice Teacher Education Programme. In this context, the emphasis on resources was oriented to interrogate resources and their use in school mathematics practice. Based on teachers' use of resources in their mathematics classroom, we reflect and delineate ways to explore the resources in the context of mathematical teaching and learning in order to promote their didactical effectiveness.
\end{abstract}

Keywords: Teacher education; resources in mathematics teaching and learning; Basic schooling.

\section{Introdução}

Tendo em consideração os resultados relativos ao desempenho de alunos portugueses em ciências e em matemática, no âmbito de estudos nacionais e internacionais, o Ministério da Educação, no quadro das medidas de política educativa para a melhoria das condições de ensino e aprendizagem da matemática e a valorização das competências dos professores, criou o Programa de Formação Contínua em Matemática (PFCM) para professores do $1^{\circ}$ Ciclo (crianças dos 6 aos 10 anos) do Ensino Básico (Despacho conjunto $n^{\circ}$ 812/2005). Trata-se de um programa, desenvolvido em articulação com as Instituições de Ensino Superior com responsabilidade na formação inicial de professores, que tem como objectivos, entre outros: (i) Promover um aprofundamento do conhecimento 
matemático, didáctico e curricular dos professores do $1^{\circ}$ ciclo envolvidos; e (ii) Favorecer a realização de experiências de desenvolvimento curricular em Matemática que contemplem a planificação de aulas, a sua condução e reflexão por parte dos professores envolvidos, apoiados pelos seus pares e formadores. Para a consecução dos objectivos estabelecidos, o Programa de Formação contempla a realização de diferentes tipos de sessões, designadamente, sessões de formação em grupo (com 8 a 10 professores) e sessões de supervisão / acompanhamento em sala de aula.

Enquanto formadora do PFCM, integrando a equipa de formação da Universidade de Aveiro-Portugal, uma das linhas orientadoras seguidas na operacionalização da formação prende-se com o considerar as práticas dos professores envolvidos na formação como ponto de partida para a (re)construção de saberes profissionais a serem reinvestidos na preparação e consecução de experiências matemáticas capazes de promover a melhoria das aprendizagens dos alunos. Nesta perspectiva, os diferentes tipos de sessões são orientados para promover o desenvolvimento do conhecimento matemático, didáctico e curricular do professor com base na reflexão na acção e sobre a acção, considerando diferentes dimensões através das quais as práticas docentes se concretizam na sala de aula. Uma dessas dimensões diz respeito aos recursos para a aula de matemática, entendidos como todos os meios a que o professor recorre, ou pode recorrer, para serem utilizados em sala de aula em apoio ao processo de ensino e aprendizagem, designadamente os recursos humanos, sociais e culturais e os recursos materiais (tais como: tecnologias, materiais manipuláveis estruturados e não estruturados, jogos, fichas de trabalho e guiões didácticos).

O interesse pelos recursos a utilizar fundamenta-se no facto de estes se poderem configurar como um importante apoio ao processo de ensino e aprendizagem. Com efeito, em documentos orientadores da acção do professor, como é o caso do Currículo Nacional do Ensino Básico: Competências Essenciais (MINISTÉRIO da EDUCAÇÃO, 2001), a utilização de recursos materiais é considerada como ponto de partida ou suporte de muitas tarefas e como meio de promover a comunicação matemática. Na mesma linha, o Programa de Matemática do Ensino Básico (PONTE et. al, 2007) refere que os alunos, em particular os do $1^{\circ}$ ciclo, devem utilizar materiais manipulativos nas situações de aprendizagem em que o seu uso seja facilitador da compreensão de ideias matemáticas. 
Mas, tal como alertam os autores, a utilização de recursos materiais só por si não garante que os alunos alcancem as aprendizagens esperadas. As potencialidades dos recursos dependem, amplamente, do uso que deles é feito. De facto, diversos estudos sugerem que diferentes professores usam os mesmos recursos de maneiras diferentes, o que se repercute diferentemente nas aprendizagens dos alunos (COHEN, RAUDENBUSH e BALL, 2003). Como ressalta Adler (2000), a efectividade dos recursos para a aprendizagem da Matemática está vinculada ao seu uso, ou seja, ao contexto de ensino e de aprendizagem que ocorre na sala de aula.

Assim sendo, no âmbito da formação de professores, designadamente, da formação contínua, os recursos na prática em contexto precisam de ser um foco de atenção (LORENZATO, 2006; ADLER, 2000). Neste quadro, reconhece-se a importância e necessidade de criar oportunidades para os professores (i) problematizarem as suas concepções acerca do papel dos recursos no processo de ensino e aprendizagem da matemática; (ii) tomarem consciência, questionarem e reflectirem sobre as suas intencionalidades ao decidirem usar determinados recursos num dado contexto educativo; (iii) avaliarem a eficácia didáctica de recursos utilizados, isto é, a sua funcionalidade como meio facilitador do processo de ensino e aprendizagem, atendendo, simultaneamente, às características dos mesmos e à forma como foram utilizados com os alunos; e (iv) perspectivarem modos de utilização de modo a potenciar a sua eficácia no contexto do ensino e aprendizagem da matemática.

\section{Os recursos materiais na prática do professor de matemática: Promover a reflexão para potenciar a acção}

Nos diversos momentos das sessões de formação em grupo, no âmbito do PFCM, as práticas dos PF constituíram-se como o foco base para o desenvolvimento de saberes a serem investidos na melhoria do processo de ensino e aprendizagem da matemática. Os exemplos a seguir apresentados ilustram o trabalho desenvolvido com os formandos no que diz respeito à dimensão dos recursos para aula a aula de matemática. A ênfase nesta dimensão orientou-se não tanto para os recursos em si, mas sobretudo para a problematização e reflexão sobre o porquê, o como e com que propósito(s) foram usados por professores envolvidos no PFCM. Decorrente desse processo de reflexão partilhada, delinearam-se modos de utilização de tais recursos de modo a promover a sua eficácia didáctica. Ao fazê-lo, criaram-se oportunidades para a clarificação e aprofundamento de conhecimento matemático, didáctico e curricular do professor de modo a tornar-se mais 
confiante e eficaz na selecção e exploração de recursos para enquadrar e orientar produtivamente o trabalho dos alunos na área da matemática.

\section{Travessia do Rio}

Implementação em sala de aula

No contexto da aula de matemática do $3^{\circ}$ ano de escolaridade ( $8 / 9$ anos), a professora Ama propôs aos alunos a realização de um jogo, o qual designou por "Travessia do Rio", tendo como propósitos: (i) fomentar o gosto pela aprendizagem da matemática; (ii) desenvolver o raciocínio; e (iii) promover a compreensão do conceito de probabilidade. Começou por apresentar a tarefa, explicitando o formato, as regras e o objectivo do jogo. De um modo resumido, a professora informou que a tarefa seria realizada em grupo de três elementos; dois deles desempenhariam o papel de jogadores (jogador A $v s$ jogador B) e outro o papel de juiz, com a função de validar as jogadas sucessivamente realizadas pelos jogadores. Informou ainda que cada grudo iria dispor de dois dados, 12 fichas amarelas (para um dos jogadores) e 12 fichas azuis (para o outro jogador) e um tabuleiro de jogo. Este ilustra um rio e respectivas margens, em cada uma das quais se encontra representado um rectângulo dividido em 12 partes geometricamente iguais ("casas"), numeradas de um a 12. Relativamente às regras do jogo, para facilitar a sua apropriação, a professora entregou uma folha com o enunciado das mesmas a cada grupo, tendo procedido à leitura, em voz alta, e explicação de cada uma delas: (i) Colocar o tabuleiro de jogo em cima da mesa; (ii) cada jogador decide em que "casa(s)" pretende colocar as suas fichas e quantas em cada caso; de acordo com essa decisão, cada o jogador dispõe as suas fichas na(s) "casa(s)" (numeradas de um a 12) correspondentes à sua "margem do rio"; (iii) cada jogador, na sua vez, lança os dados e calcula a soma das pintas saídas; (iv) no caso de a soma obtida corresponder a uma "casa" em que o jogador tem uma (ou mais) fichas, tem direito a mudar uma ficha para a outra "margem do rio". Ganha o jogador que primeiro conseguir transpor todas as suas fichas para a outra "margem do rio".

Uma vez constituídos os grupos e distribuídos os recursos necessários à realização do jogo, desenvolveu-se a tarefa. Estabelecidos os jogadores e o juiz, cada grupo realizou uma partida do jogo. Terminada a primeira partida do jogo, os elementos de cada grupo, trocaram de papéis e realizaram outras partidas do jogo até todos terem desempenhado o papel de juiz. 
Após o desenvolvimento da tarefa, a professora solicitou aos alunos que fizessem a avaliação do trabalho realizado mediante o preenchimento de um questionário com quatro questões, concretamente: (1) Sentiste dificuldades? Se sim, quais?; (2) Em que aspectos é que esta tarefa contribui para melhorar os teus conhecimentos?; e (3) Como reparaste nunca surgiu o número um. Explica porquê.

\section{$\underline{\text { Reflexão sobre a acção }}$}

No contexto da reflexão partilhada no grupo de formação, após a professora Ama ter relatado o trabalho realizado pelos alunos, dando conta do seu envolvimento do desempenho no contexto do mesmo, os PF foram convidados a realizar o jogo, a pares. Em seguida, deu-se oportunidade a cada um de explicitar raciocínios feitos, estratégias usadas e conhecimentos matemáticos mobilizados. Nesta sequência, identificaram-se potencialidades do jogo para promover aprendizagens matemáticas, identificando capacidades, atitudes e conhecimentos matemáticos que o mesmo pode ajudar a desenvolver; confrontaram-se tais potencialidades com o ocorrido em sala de aula e questionou-se o que poderia (deveria) ser feito de modo diferente para que o jogo em causa fosse um suporte mais efectivo para os alunos desenvolverem compreensão acerca de situações aleatórias e de acontecimentos mais ou menos prováveis. De tal discussão emergiram alguns aspectos. Um deles diz respeito à importância e necessidade de fazer registos. Nesse sentido, em cada grupo, seria desejável que o aluno com o papel de juiz (orientador do jogo) dispusesse de uma folha de registos do tipo da a seguir apresentada:

1. Para cada jogador, regista a quantidade de fichas colocadas em cada um dos números da respectiva margem do rio.

\begin{tabular}{|l|l|l|l|l|l|l|l|l|l|l|l|l|}
\hline $\begin{array}{c}\text { Números } \\
\text { Jogador }\end{array}$ & $\mathbf{1}$ & $\mathbf{2}$ & $\mathbf{3}$ & $\mathbf{4}$ & $\mathbf{5}$ & $\mathbf{6}$ & $\mathbf{7}$ & $\mathbf{8}$ & $\mathbf{9}$ & $\mathbf{1 0}$ & $\mathbf{1 1}$ & $\mathbf{1 2}$ \\
\hline & & & & & & & & & & & & \\
\hline & & & & & & & & & & & & \\
\hline
\end{tabular}

2. Para cada jogador, regista a soma das pintas saídas no lançamento dos dados em cada jogada realizada.

\begin{tabular}{|c|c|c|}
\hline & Soma das pintas saídas no lançamento dos dois dados \\
\hline Número da jogada & Jogador: & Jogador: \\
\hline $1^{\mathrm{a}}$ & & \\
\hline $2^{\mathrm{a}}$ & & \\
\hline $3^{\mathrm{a}}$ & & \\
\hline$\ldots$ & & \\
\hline$\ldots$
\end{tabular}

43 REVEMAT - Revista Eletrônica de Educação Matemática. V4.1, p.39-52, UFSC: 2009. 
Um outro aspecto emergente da discussão prendeu-se com a necessidade de criar momentos na aula para os alunos discutirem e reflectirem sobre o modo como pensaram e actuaram no contexto do jogo. Assim, após os alunos terem realizado uma vez o jogo, justifica-se o criar uma primeira oportunidade para a partilha e discussão acerca do mesmo, com o propósito de promover a reflexão sobre a acção e, consequentemente, a (re)construção de conhecimento matemático. Nesse sentido e com base nos registos feitos pelo orientador do jogo, o professor pode questionar os alunos, com base em questões como:

$\checkmark$ Em que números colocaram fichas? Porquê nesses números?

$\checkmark$ Houve algum número no qual não colocaram fichas? Porquê?

$\checkmark$ Colocaram o mesmo número de fichas nos diferentes números que assinalaram? Se não, em que número(s) colocaram mais (menos) fichas? Porquê nesse(s)?

$\checkmark$ Quais as somas que se poderiam obter no lançamento dos dados?

$\checkmark$ No lançamento dos dados, qual a soma que se repetiu mais vezes (que saiu mais vezes)? Por que é que tal terá acontecido?

$\checkmark$ E, qual a soma que se registou um menor número de vezes (a soma que menos vezes saiu no lançamento dos dados)? Por que é que tal terá acontecido para esse caso?

$\checkmark$ Em cada equipa, quem foi o vencedor? O vencedor ganhou apenas porque teve mais sorte, ou há também outras razões? Se sim, quais?

Após a partilha e discussão, os alunos podem ser convidados a realizar novamente o jogo, podendo em cada grupo de três, desempenhar o papel de orientador de jogo o aluno que venceu a partida anterior. Pretende-se, deste modo, criar oportunidades para mobilizarem conhecimento matemático importante para criar melhores condições para vencer o jogo.

Após os alunos terem jogado, novamente, o jogo dever-se-á promover a partilha e discussão acerca do mesmo e ajudar os alunos a sistematizarem as aprendizagens feitas. Para tal, poder-se-á formular questões como:

$\checkmark$ Em que números colocaram fichas? Porquê nesses?

$\checkmark$ Houve algum número no qual não colocaram fichas? Porquê? 
O que fizeram de maneira diferente relativamente à primeira vez que jogaram? O que vos levou a fazê-lo?

$\checkmark$ Em cada equipa, quem foi o vencedor? O vencedor ganhou apenas porque teve mais sorte, ou há também outras razões? Se sim, quais?

Com o propósito de sistematizar a aprendizagem de conhecimento matemático no âmbito do domínio temático "probabilidades", poder-se-á começar por solicitar aos alunos que construam uma tabela na qual possam registar todas as somas que poderiam sair no lançamento dos dois dados.

Exemplo:

\begin{tabular}{|c|c|c|c|c|c|c|c|}
\cline { 3 - 8 } \multicolumn{2}{c|}{} & \multicolumn{7}{c|}{ Dado A } \\
\cline { 2 - 8 } \multicolumn{2}{c|}{} & 1 & 2 & 3 & 4 & 5 & 6 \\
\hline \multirow{4}{*}{ Dado B } & 1 & 2 & 3 & 4 & 5 & 6 & 7 \\
\cline { 2 - 8 } & 2 & 3 & 4 & 5 & 6 & 7 & 8 \\
\cline { 2 - 8 } & 3 & 4 & 5 & 6 & 7 & 8 & 9 \\
\cline { 2 - 8 } & 4 & 5 & 6 & 7 & 8 & 9 & 10 \\
\cline { 2 - 8 } & 5 & 6 & 7 & 8 & 9 & 10 & 11 \\
\cline { 2 - 8 } & 6 & 7 & 8 & 9 & 10 & 11 & 12 \\
\hline
\end{tabular}

Com base no registo feito, poder-se-ão formular questões como:

$\checkmark$ Dá um exemplo de uma soma que seja um acontecimento impossível no lançamento dos dois dados?

Quais as somas possíveis de obter no lançamento dos dois dados?

$\checkmark$ Qual a soma mais provável de obter? Porquê?

$\checkmark$ Qual a soma menos provável de obter? Porquê?

$\checkmark$ Ordena as somas possíveis de obter por ordem crescente de probabilidade de ocorrerem.

As sugestões acabadas de apresentar evidenciam uma utilização e exploração diferentes do jogo "travessia do rio", mais focada em aspectos essenciais à aprendizagem da matemática. A reflexão ocorrida no seio do grupo de formação, tendo por base o trabalho realizado em sala de aula, constituiu-se como uma oportunidade para os professores em formação aprofundarem conhecimento matemático, didáctico e curricular. Tais conhecimentos foram mobilizados no perspectivar um modo e utilização do mesmo jogo que se configura como mais funcional. Isto, porque há uma intencionalidade clara em promover o conhecimento matemático dos alunos relativo a situações aleatórias. 


\section{Desafios com dominós}

Implementação em sala de aula

Tendo por base o jogo do dominó convencional, a professora Lu propôs aos alunos do $1^{\circ}$ ano de escolaridade, em várias aulas, tarefas orientadas para o desenvolvimento do sentido de número e da fluência de cálculo. De um modo mais específico, o conjunto de tarefas propostas foi delineado de modo a permitir às crianças a compreensão e facilidade em lidar com os sentidos ordinal e cardinal do número; compor e decompor números, estabelecer relações numéricas; usar diferentes representações para um mesmo número natural; e adicionar números naturais utilizando a representação horizontal e recorrendo a estratégias de cálculo mental e escrito.

No âmbito da primeira tarefa, começou por apresentar aos alunos o jogo, mostrando-lhes uma caixa com o dominó. Solicitou-lhes que fizessem uma estimativa do número de peças do jogo. Em seguida, procederam à contagem das peças, confrontaram o valor exacto com o valor estimado por cada um e avaliaram as estimativas feitas.

No contexto da segunda tarefa realizada, cada aluno retirou da caixa uma peça; observou-a e representou-a, numa folha de registo fornecida para o efeito e, utilizando a representação horizontal, adicionaram as pintas de cada parte da peça. No momento da partilha com a turma trabalho feito por cada um, a professora formulou questões como, por exemplo: (1) Quantas pintas tem a peça retirada pela Ana?"; Quem tem uma peça com igual número de pintas?; (2) Qual a peça que tem mais pintas: a retirada pelo Zé ou a retirada pela Ana? Quantas a mais?; (3) Quantas pintas tem a peça retirada pelo Rui? E a peça retirada pela Maria? Quantas pintas faltam à peça do Rui para ter tantas pintas quantas as da peça retirada pela Maria?".

Numa outra tarefa, envolveu os alunos na realização de um jogo que foi designado por "Uma pinta a menos... uma pinta a mais...". Apresentou a tarefa e explicitou o que esperava dos alunos. Esclareceu que o professor ia desempenhar o papel de orientador de jogo e cada grupo de quatro alunos formava uma equipa. Neste âmbito, foi referido que o orientador do jogo retirava sucessivamente seis peças de dominó que afixava no quadro. Para cada peça saída, cada equipa devia, caso fosse possível, representar na coluna respectiva da sua folha de registo: (i) a peça saída, (ii) uma peça com uma pinta a menos e (iii) uma peça com uma pinta a mais, indicando em cada caso o total de pintas da peça. Após terem sido extraídas as seis peças (seis jogadas), seriam validados os registos feitos por cada equipa. $\mathrm{O}$ vencedor do jogo seria a equipa que cometesse menos erros. 
Na sequência da realização do jogo e para proceder à validação das jogadas, a professora desenhou no quadro a folha de registo. Para cada jogada, solicitou às equipas que representassem no quadro a resposta dada. Estas foram analisadas, discutidas e avaliadas em grande grupo.

Com base no registo feito, a professora promoveu a reflexão sobre o trabalho realizado com base em questões como: (1) Todas as jogadas admitiam uma única resposta correcta? Porquê? Dá exemplos de jogadas que admitiam mais do que uma resposta aceitável? Explica por que razão tal aconteceu? (2) Houve alguma jogada em que a resposta correcta era única? Se sim, qual? Explica por que é que tal aconteceu nesse caso?; (3) Em alguma situação não foi possível representar uma peça com uma pinta a mais (a menos) do que a quantidade de pintas da peça saída? Porque é que tal aconteceu?

A professora Maria, recorrendo também ao jogo de dominó convencional, propôs aos seus alunos do $3^{\circ}$ ano a realização de vários desafios. Tais desafios pretendiam configurar-se como situações estimulantes e desafiantes capazes de fomentar o gosto dos alunos pela matemática, bem como promover a compreensão dos números e das operações, desenvolver o sentido de número e a fluência de cálculo mobilizando, nomeadamente, conhecimentos sobre os efeitos de uma operação sobre os números e as propriedades das operações com números naturais.

Num primeiro desafio, os alunos, em trabalho de pares, foram solicitados a construir uma moldura quadrangular, usando 4 peças de dominó, de modo que a soma das pintas das peças colocadas em cada lado fosse sempre a mesma. Um outro desafio, pedia aos alunos que usando determinadas peças do dominó (concretamente, as peças: 3-1; 1-6; 6-3; e 3-2), construíssem uma moldura quadrangular de modo que o produto das pintas das peças colocadas em cada lado fosse sempre 18. Num outro desafio os alunos eram convidados a seleccionarem do dominó a peça "2-3" e todas as peças que tivessem ausência de pintas numa ou em ambas as partes; com as peças seleccionadas deviam construir uma moldura rectangular de modo que o total de pintas das peças colocadas em cada lado fosse sempre nove.

No desenvolvimento dos desafios propostos, a professora acompanhou o trabalho dos alunos incentivando-os a agir reflectidamente, prevendo as consequências de acções antes de as concretizarem.

Após a realização dos desafios, cada par foi solicitado a comunicar e partilhar com os outros o modo como pensaram para resolver cada desafio e a solução alcançada. Neste processo, a professora assumiu o papel de dinamizadora da comunicação e reflexão 
formulando questões como: Que peça escolheram primeiro? Porquê?; Como foram colocando as restantes peças?; e Como foram controlando o número de pintas pretendido?. Por fim, os alunos foram solicitados a elaborar um texto escrito, relatando o que fizeram, como fizeram e o que aprenderam.

\section{$\underline{\text { Reflexão sobre a acção }}$}

Tendo em consideração o conjunto de desafios com dominós, ressalta a intencionalidade no uso deste recurso para promover explicitamente aprendizagens no âmbito do tema Números e Operações. Tal intencionalidade está patente não só nas tarefas planificadas, mas também no modo como foram orientadas em sala de aula. A este nível, é de sublinhar os registos solicitados aos alunos, os momentos de discussão criados, o questionamento do professor, bem como as oportunidades de produção escrita e de sistematização de conhecimentos e ideias matemáticas. Através discussão e da produção de registos e textos escritos, os alunos tiveram oportunidade de clarificar e aprofundar o seu pensamento matemático, progredindo no uso de uma linguagem que se pretende cada vez mais clara e rigorosa, fazendo uso de vocabulário específico da matemática.

O reconhecimento da eficácia didáctica dos desafios com dominós propostos aos alunos, motivou os professores em formação a planificarem outras situações de aprendizagem conjugando as potencialidades do recurso com modos de utilização tendo em consideração propósitos visados. A título ilustrativo, a propósito do jogo "Uma pinta a menos... uma pinta a mais...", foi desenvolvida uma versão envolvendo o extrair não de uma mas de duas peças de dominó, sendo os alunos desafiados a representar também um par de peças com uma pinta a menos e um par com uma pinta a mais. Além disso, os alunos deviam posicionar numa recta numérica os números correspondentes, em cada jogada, a soma das pintas de cada par de peças (par de peças extraídas, par de peças com uma pinta a menos e par de pintas com uma pinta a mais). Deste modo, criam-se oportunidades para o desenvolvimento do sentido de número, conjugando o sentido cardinal e o sentido ordinal, enfatizando o estabelecer de relações numéricas e estratégias de cálculo.

\section{Imagens rápidas}

$\underline{\text { Implementação em sala de aula }}$

Com o propósito principal de promover o cálculo mental dos alunos, a professora Bea propôs aos seus alunos do $2^{\circ}$ ano de escolaridade um jogo que envolvia o uso de 
cartões com representações de números até 200. No âmbito do mesmo, primeiro a professora estabelecida a operação a usar (adição, subtracção e multiplicação); depois levantava dois cartões, em cada um dos quais se encontrava representado um número natural; o aluno mais rápido a fazer o cálculo, usando a operação estabelecida e os números representados, ganhava um ponto. Atingidas as jogadas previamente estipuladas, o aluno com mais pontos ganhava o jogo. Numa outra versão do jogo, a professora definiu que em cada jogada, os alunos deviam assinalar, na sua folha de registo, o número correspondente à soma dos números representados nos cartões levantados.

Também com o propósito de promover o cálculo mental com base no estabelecer de relações numéricas de referência, a professora Paula propôs aos seus alunos do $1^{\circ}$ ano um jogo que envolvia o uso de cartas de um baralho convencional. A professora começou por mostrar um baralho de cartas, informando os alunos que iam realizar um jogo com algumas daquelas cartas, concretamente com as cartas do "dois" ao "dez" e ainda as cartas jocker. Uma vez formados os grupos e identificadas as equipas, distribuiu um conjunto de cartas a cada grupo. Solicitou a um dos elementos de cada grupo que distribuísse igualmente as cartas por ambas as equipas (equipa A vs equipa B). Nesse momento, explicou que cada equipa devia observar as cartas saídas de modo a formar o maior número possível de "pares de dez", isto é, pares de cartas em que a soma dos números nelas representados fosse 10. Acrescentou ainda que a equipa que tivesse uma ou mais cartas jocker, lhe(s) podia atribuir o número que mais lhe conviesse para tentar formar mais um "par de dez".

Na sequência da realização de uma primeira partida do jogo, cada equipa colocou em cima da mesa os pares formados. A professora, solicitou a cada equipa que comunicasse à turma os pares formados. À medida que os alunos o faziam, a professora procedia ao registo no quadro. Com base na análise e discussão desse registo, os alunos foram envolvidos na validação dos pares formados por cada equipa.

\section{$\underline{\text { Reflexão sobre a acção }}$}

No contexto da reflexão sobre a acção, sublinhou-se a importância e necessidade de propor situações diversificadas, explicita e intencionalmente orientadas para o desenvolvimento do cálculo mental dos alunos, capazes de suscitar o uso de diversas estratégias baseadas na composição e decomposição de números, nas propriedades das operações e nas relações entre números e operações. Nesta linha, um aspecto alvo de 
reflexão teve a ver com as estratégias de cálculo mental mais adequadas às situações propostas aos alunos nas diferentes tarefas implementadas em sala de aula.

Reconhecendo que as estratégias de cálculo mental devem ser objecto de aprendizagem, equacionaram-se situações a propor aos alunos para fomentar o desenvolvimento de outras estratégias de cálculo. Um outro aspecto focado prendeu-se com a importância da existência de momentos da aula para os alunos poderem explicitar as estratégias de cálculo usadas. Isto, porque, tal como referido no Programa de Matemática do Ensino Básico (PONTE et. al, 2007), a explicitação pelos alunos das estratégias usadas e a discussão das mesmas em grande grupo poderá ajudá-los a desenvolver um leque mais amplo de estratégias, bem como a tornar-se mais versados e flexíveis no uso de diferentes estratégias de cálculo mental, seleccionando as mais adequadas para cada situação.

\section{Considerações finais}

A eficácia de um recurso para a aprendizagem da matemática reside no seu uso em contexto e não na sua mera presença. Até, porque, ao usar-se um determinado recurso para promover a aprendizagem matemática, em algum momento é necessário que este se torne invisível; tal significa que o recurso em si não é o objecto de atenção dos alunos mas um meio para fazerem matemática (ADLER, 2000). Um recurso pode ser usado, por exemplo, para apoiar os alunos na resolução de um problema e/ou na formulação e teste de conjecturas. Após a apreensão dos conceitos envolvidos na actividade, o recurso deverá ser abandonado, progredindo-se para uma abordagem mais formal e sistematizadas do(s) conceito(s) ou ideias matemáticas em causa.

Assim sendo, a selecção e modo(s) de utilização de um recurso em sala de aula o devem ser racionalmente decididas pelo professor, tendo em consideração as aprendizagens a realizar pelos alunos. Para tal, importa não só que o professor tenha acesso a diversificados recurso, mas sobretudo que questione e reflicta sobre o como os mesmos podem e devem ser usados em contexto como suporte do desenvolvimento do poder matemático dos alunos.

A este nível, o trabalho desenvolvido com os PF evidencia a importância das reflexões partilhadas sobre o modo como determinados recursos foram usadas. Tais reflexões configuraram-se como oportunidades para promover o conhecimento matemático, didáctico e curricular dos professores, o qual se repercute no uso que fazem dos recursos para enquadrar produtivamente as tarefas propostas aos alunos e potenciar a sua actividade matemática. Como sublinha Alarcão (2007), “[...] o diálogo com a situação 
não pode quedar-se a um nível meramente descritivo, pois seria extremamente pobre. Tem de atingir um nível explicativo e crítico que permita aos profissionais de ensino agir e falar com o poder da razão" (p. 46).

De facto, na sequência do trabalho realizado, alguns PF tomaram consciência e reconheceram que, muitas vezes, seleccionam recursos com base em aspectos acessórios à aprendizagem da matemática, como, por exemplo o seu potencial para motivar os alunos, nunca chegando o recurso a tornar-se invisível. Reconheceram ainda que inseguranças a nível do conhecimento matemático e de conhecimento didáctico de conteúdo leva-os, muitas vezes, a não centrarem a atenção em aspectos essenciais à aprendizagem da matemática.

Decorrente do trabalho realizado nas sessões de formação, os PF reconstruíram ideias e práticas no tocante à dimensão dos recursos. Estes passaram a ser seleccionados, ou elaborados, e usados de um modo mais racional. A este último nível, é de salientar a preocupação com os registos solicitados aos alunos, bem como com a gestão do tempo de aula de modo a criar momentos para a partilha e discussão do trabalho realizado, tendo em vista o criar oportunidades para o desenvolvimento de capacidades, designadamente de capacidades de comunicação, bem como para a clarificação, (re)construção, aprofundamento, sistematização e estruturação de ideias e conhecimentos matemáticos.

Nos diferentes momentos da aula, incluindo os momentos de trabalho em grande grupo, tendentes a envolver todos os alunos na partilha, discussão e reflexão sobre o trabalho realizado, o questionamento do professor é extremamente importante (VIEIRA E TENREIRO-VEIRA, 2005). O questionamento do professor, nos diferentes momentos da aula, com base em questões provocativas do pensamento e que têm em atenção as ideias dos alunos sobre um assunto ou tópico específico podem potenciar a actividade matemática do aluno, ajudando a clarificar, organizar e elaborar o seu pensamento e a encontrar respostas de uma modo mais compreensivo. Tanto mais que, os alunos aprendem não só a partir das actividades que realizam, mas sobretudo da discussão e reflexão que efectuam sobre essas actividades.

\section{Referências}

ADLER, J. Conceptualising resources as a theme for teacher Education. Journal for Mathematics Teacher Education, v.3, n. 3, p. 205-24. 2000.

ALARCÃO, I. Professores reflexivos em uma escola reflexiva. (5 $5^{\mathrm{a}}$ ed.). São Paulo: Cortez Editora, 2007. 
COHEN, D., RAUDENBUSH, S., \& BALL, D. Resources, instruction and research. Educational Evaluation and Policy Analysis, 25 (2), 119-142, 2003. [http://wwwpersonal.umich.edu/ dball/articles/ResourcesEEPA2003.pdf] (acedido em Julho de 2008) LORENZATO, Sérgio. O laboratório de ensino de matemática na formação de professores. Campinas: Autores Associados, 2006.

ME \& MCTES. Despacho conjunto nº 812/2005. Diário da República, II Série, 24 de Outubro de 2005. (pp. 15090-15092)

ME. Plano de Acção para a Matemática. Lisboa: 2006.

ME (2001). Currículo nacional do ensino básico: Competências essenciais. Lisboa, 2001.

PONTE, J. P., et al. Programa de Matemática do Ensino Básico. Lisboa: Ministério da Educação, Direcção Geral de Inovação e de Desenvolvimento Curricular, 2007.

VIEIRA, R. e TENREIRO-VIEIRA, C. Estratégias de ensino / aprendizagem. Lisboa: Editorial Instituto Piaget, 2005. 